Smith, E. E. B., Mrlls, G. T., Harper, E. M. \& Galloway, B. (1957). J. gen. Microbiol. 17, 437-444

\title{
The Gellular Polysaccharide of a Type II non-capsulated Pneumococcus
}

\author{
BY EVELYN E. B. SMITH, G. T. MILLS, ELIZABETH M. HARPER \\ AND B. GALLOWAY
}

The Department of Biochemistry and the Department of Bacteriology, University of Glasgow

SUMMARY : A purified cellular polysaccharide was obtained from a non-capsulated pneumococcus (Streptococcus pneumoniae, strain R19, derived from a Type II organism). The main purification steps were peptic, tryptic and ribonuclease digestions, removal of protein by the Sevag technique and ethanol precipitation of the polysaccharide. Ribonuclease digestion was an essential step in the purification procedure. The constituent sugars of the isolated polysaccharide were galactose, mannose and glucosamine. The acetyl content of the polysaccharide indicated that the glucosamine was fully acetylated on the $\mathrm{N}$ position and that some $O$-acetyl was also present. The phosphorus content was not entirely explicable in terms of the known ribonucleic acid (RNA) and deoxyribonucleic acid (DNA) contamination. Residual amino acid was consistently present which may have been due to bound amino acids or to protein contamination.

A study of the uridine pyrophosphoglycosyl compounds of the pneumococcus (Smith, Mills \& Harper, 1957 a) showed the presence of uridine pyrophosphoglucose (UPPglucose) and uridine pyrophosphoglucuronic acid (UPPglucuronic acid) in Streptococcus pneumoniae, strain R19, derived from a Type II organism, and in a capsulated $S$. pneumoniae, Type III, strain A66. The uridine pyrophosphoglycosyl compound, uridine pyrophosphogalacturonic acid (UPPgalacturonic acid), has also been isolated from a capsulated $S$. pneumoniae Type I (Smith, Mills \& Harper, 1957 b). It was suggested by the above authors that such uridine derivatives function as sugar-transferring agents in the synthesis of the capsular polysaccharides of $S$. pneumoniae. Uridine pyrophosphoacetylglucosamine (UPPacetylglucosamine) has also been isolated in considerable amounts from all the above pneumococcal types, and it has been proposed (Smith et al. 1957a) that this compound is functional in synthesis of the cellular polysaccharide of pneumococci. It was therefore considered essential to investigate the structure of this polysaccharide to determine whether or not acetylglucosamine is a constituent of this material.

Information about composition of the cellular polysaccharide of pneumococci is scant. In 1930 Enders, utilizing an autolysate from a Type I pneumococcus, obtained an immune rabbit serum by repeated injections of the autolysate; when the serum was tested against the type-specific polysaccharide no precipitate was formed, but with an autolysate from smooth Type I pneumococcus the serum gave a definite precipitin reaction. An effect analogous to that described by Enders was reported by Sabin (1931), by Wadsworth \& 
Brown (1931) and by Ward (1932). Wadsworth \& Brown (1933) separated carbohydrate fractions from pneumococci types I, II and III, and also from an atypical strain. The preparations were essentially different from the typespecific substance and were designated as cellular carbohydrate. Micro-analysis of the cellular carbohydrates yielded phosphorus values ranging from $0 \cdot 43$ to $6.54 \%$ and total nitrogen values ranging from 3.03 to $8.92 \%$; amino-N was also shown to be present. Wadsworth, Crowe \& Smith (1934) studied the absorption spectra of cellular polysaccharide preparations at different stages of purification and found that selective absorption in the ultraviolet region was characteristic of the pure substance.

Tillett \& Francis (1930) isolated from a non-type-specific $R$ strain of pneumococcus a substance called fraction $\mathrm{C}$; this fraction was chemically distinct from the type-specific capsular carbohydrate and exhibited no type specificity. Tillett, Goebel \& Avery (1930) studied the newly isolated fraction which was shown to contain $\mathbf{5 . 0 7} \%$ nitrogen, yielded $30 \%$ of reducing sugars on hydrolysis and contained no amino-N. The fraction exhibited a broad species coverage but no type specificity; the conclusion was that fraction $\mathrm{C}$ was a common constituent of all pneumococci. Heidelberger \& Kendall (1931) further separated pneumococcal cellular polysaccharide into an immunologically inactive fraction and an immunologically active fraction identical with the $\mathrm{C}$ fraction. The serologically inactive fraction differed from fraction $\mathrm{C}$ in yielding on hydrolysis crystals with the optical rotation of glucosamine. The most comprehensive review of these findings is that of White (1938). The present paper describes the isolation of a polysaccharide from an extreme rough non-capsulated Streptococcus pneumoniae derived from a Type II organism.

\section{METHODS}

The organism used was a non-capsulated Streptococcus pneumoniae Type II, strain R 19, kindly supplied by Dr R. D. Hotchkiss (Rockefeller Institute for Medical Research, New York, U.S.A.). Large-scale cultivation in 3.7\% (w/v) Bacto brain heart infusion medium at $\mathbf{~} \mathbf{H} \mathbf{7 \cdot 4}$ and harvesting of the organisms in the Sharples Supercentrifuge were carried out as described by Smith et al. (1957a).

Bacto brain heart infusion (solid), pepsin and trypsin were obtained from Difco Laboratories, Detroit, Michigan, U.S.A.

Crystalline ribonuclease was obtained from Armour Laboratories, U.S.A.

Total nitrogen was determined by the micro-Kjeldahl method, using the Markham distillation unit (Ma \& Zuazaga, 1942).

Glucosamine was estimated by the method of Rondle \& Morgan (1955); acetyl groups were determined by a micro-modification of the method of Heidelberger, Kendall \& Scherp (1936), which allowed determinations of the order of 0.2-1.0 mg. acetyl; $D N A$-deoxyribose estimations were carried out by the method of Ceriotti (1955) as modified by Paul (1956) and micro-phosphorus estimations by the method of Griswold, Humoller \& McIntyre (1951). Determination of total reducing sugar was carried out by the method of Hagedorn \& 
Jensen (1923). Paper chromatography of sugars was carried out in the butanol/acetic acid/water solvent and the butanol/ethanol/water solvent of Partridge (1948) on Whatman no. 1 paper; the method of Consden \& Stanier (1952) was employed for ionophoresis of sugars as borate complexes on Whatman 3 MM paper strips; the aniline hydrogen phthalate reagent of Partridge (1949) was used for the development of the sugar spots. Amino acid chromatography was carried out on Whatman no. 1 paper using the two-dimensional butanol/acetic acid/water and phenol/ammonia system (Partridge, 1948). Purine base and pyrimidine nucleotide chromatography was carried out in the isopropanol/HCl solvent of Wyatt (1951).

\section{RESULTS}

\section{Purification of the polysaccharide}

The centrifuged organisms from $8 \mathrm{l}$. culture medium were suspended in $500 \mathrm{ml}$. distilled water, the $\mathrm{pH}$ value adjusted to $\mathrm{pH}$ 1-2 with dilute $\mathrm{HCl}$ and $\mathbf{1}$ g. pepsin added; digestion was allowed to proceed for $24 \mathrm{hr}$. at $37^{\circ}$. At the end of this period the $\mathrm{pH}$ value was adjusted to 9 with $2 \mathrm{~N}-\mathrm{KOH}, 2 \mathrm{~g}$. trypsin added and digestion continued for a further 2 days at $37^{\circ}$. Tryptic activity was destroyed by neutralizing the digest and bringing it rapidly to the boil; the digest was then cooled rapidly to $30^{\circ}-37^{\circ}$.

The $\mathrm{pH}$ value was readjusted to $7 \cdot 8$ with dilute $\mathrm{KOH}$ and $100 \mathrm{mg}$. crystalline ribonuclease added, followed by incubation at $37^{\circ}$ for $3 \mathrm{hr}$. The $\mathrm{pH}$ value was again readjusted to 9 and a further tryptic digestion made by adding 1 g. trypsin and a $24 \mathrm{hr}$. incubation period at $37^{\circ}$.

At the end of this period the solution was filtered, $10 \mathrm{~g}$. sodium acetate, $1 \mathrm{ml}$. acetic acid, $20 \mathrm{ml}$. chloroform and $4 \mathrm{ml}$. $n$-butanol added for every $100 \mathrm{ml}$. solution and protein removed exhaustively by the method of Sevag (1934).

The polysaccharide was precipitated from solution by the addition of 5 vol. ethanol, centrifuged and washed with $95 \%(\mathrm{v} / \mathrm{v})$ ethanol in water followed by an ether washing; the material so obtained was dried in vacuo. The dried product was dissolved in $50 \mathrm{ml}$. water and dialysed for 2 days at $0^{\circ}$ against several changes of distilled water. The insoluble residue obtained on dialysis was discarded and the polysaccharide was reprecipitated from solution by the addition of sodium acetate $(10 \mathrm{~g} . / 100 \mathrm{ml}$.$) , acetic acid (1 \mathrm{ml} . / 100 \mathrm{ml}$.$) and$ 5 vol. ethanol. The centrifuged polysaccharide was washed with $95 \%(\mathrm{v} / \mathrm{v})$ ethanol in water followed by an ether washing and was then dried in vacuo; yield $50 \mathrm{mg}$.

\section{Analysis and properties of the polysaccharide}

Constituent sugars obtained by acid hydrolysis. Five mg. of the isolated polysaccharide were hydrolysed with $1 \mathrm{ml} . \mathrm{N}_{-} \mathrm{H}_{2} \mathrm{SO}_{4}$ at $110^{\circ}$ for $18 \mathrm{hr}$. and the hydrolysate neutralized with solid $\mathrm{BaCO}_{3}$. The precipitated $\mathrm{BaSO}_{4}$ was removed by centrifugation, washed with $1 \mathrm{ml}$. water, recentrifuged, the supernatant fluids pooled and dried in vacuo. The dried material was dissolved in $500 \mu \mathrm{l}$. distilled water, any further trace of $\mathrm{BaSO}_{4}$ removed by centrifugation, 
and $50 \mu \mathrm{l}$. samples were then taken for paper chromatography and ionophoresis. As will be seen from Table 1, the constituent sugars of the isolated polysaccharide obtained by hydrolysis were galactose, mannose and glucosamine; galactose was the major component.

\section{Table 1. Constituent sugars of the cellular polysaccharide from} Streptococcus pneumoniae Type II, strain $R 19$

$\boldsymbol{R}_{\text {gluose }}$ values by chromatography in two solvents and ionophoresis in borate buffer at pH 8.6.

\begin{tabular}{|c|c|c|c|}
\hline \multirow{3}{*}{$\begin{array}{l}\text { Polysaccharide } \\
\text { hydrolysate }\end{array}$} & $\begin{array}{l}\text { Butanol/acetic } \\
\text { acid/water }\end{array}$ & $\begin{array}{c}\text { Butanol/ethanol/ } \\
\text { water }\end{array}$ & Ionophoresis \\
\hline & 0.65 & 0.70 & 0.53 \\
\hline & $\begin{array}{l}0.85 \\
1.26\end{array}$ & $\begin{array}{l}0.90 \\
1.24\end{array}$ & $\begin{array}{l}0.82 \\
0.91\end{array}$ \\
\hline Glucosamine & 0.66 & $0 \cdot 72$ & 0.52 \\
\hline Mannose & 1.27 & 1.27 & 0.81 \\
\hline Galactose & 0.84 & 0.89 & 0.92 \\
\hline
\end{tabular}

Trace amounts of ribose (probably from RNA contamination) were identified in both chromatographic solvents.

Glucosamine content. Fig. 1 shows the liberation of glucosamine from the polysaccharide during hydrolysis at $100^{\circ}$ with $3 \mathrm{~N}-\mathrm{HCl}$ as measured by the method of Rondle \& Morgan (1955); $3 \mathrm{~N}-\mathrm{HCl}$ gave optimal liberation of glucosamine from the polysaccharide. Glucosamine standards were run simultaneously.

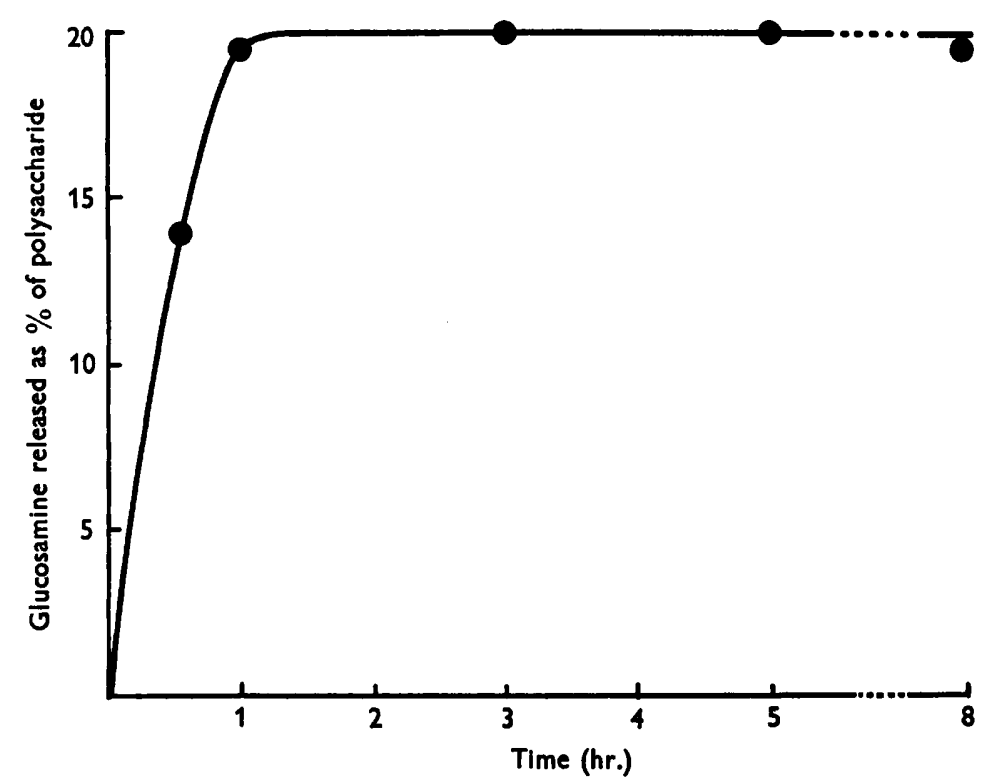

Fig. 1. Liberation of glucosamine as measured by the method of Rondle \& Morgan (1955) from the polysaccharide during hydrolysis at $100^{\circ}$ with $3 \mathrm{~N}-\mathrm{HCl}$. 
$\mathrm{N}$-acetyl and $\mathrm{O}$-acetyl evaluations. Total acetyl was determined by steam distillation of acetic acid from the polysaccharide after hydrolysis with $p$-toluenesulphonic acid. The method of Heidelberger et al. (1936) was modified by using a micro-distillation unit with subsequent titration of acetic acid with the Conway burette (1947). The results are recorded in Table 2. It will be observed that the acetyl content of the polysaccharide was greater than can be accounted for by $N$-acetylation of the glucosamine present; hence the following experiment was carried out to determine $\boldsymbol{O}$-acetyl groups by means of their lability to alkali (Smith \& Zwartouw, 1956). Six mg. polysaccharide in $1 \mathrm{ml} .2 \%(\mathrm{w} / \mathrm{v}) \mathrm{KOH}$ were allowed to stand at room temperature for $30 \mathrm{~min}$.; $10 \mathrm{ml}$. cold ethanol was added and the precipitated polysaccharide washed twice with ethanol $(5 \mathrm{ml}$.). The acetyl content of the recovered polysaccharide is shown in Table 2, the results indicating that approximately $50 \%$ of the total acetyl in the polysaccharide was $\mathrm{N}$-acetyl. The values correspond to complete acetylation of the glucosamine found in the polysaccharide.

Table 2. Analysis of the cellular polysaccharide from Streptococcus pneumoniae Type II, strain $R 19$

$\begin{array}{lc} & \% \\ \text { Total reducing sugar (calculated as glucose) } & \mathbf{6 0} \\ \text { Glucosamine } & \mathbf{2 0} \\ \text { Galactose + mannose (calculated) } & \mathbf{4 5} \\ \text { Total acetyl } & \mathbf{1 0 \cdot 0} \\ N \text {-acetyl } & \mathbf{5 \cdot 3} \\ \text { Total nitrogen } & \mathbf{4 \cdot 8} \\ \text { Total phosphorus } & \mathbf{1 \cdot 3} \\ \text { RNA-phosphorus } & \mathbf{0 \cdot 7} \\ \text { DNA-phosphorus } & \mathbf{0 \cdot 0 5}\end{array}$

Total reducing sugar. Hydrolysis of the polysaccharide with $3 \mathrm{~N}-\mathrm{HCl}$ at $100^{\circ}$ for $3 \mathrm{hr}$. provided optimal conditions for liberation of reducing groups. Such hydrolysates were dried in vacuo, and total reducing sugar estimated by the method of Hagedorn \& Jensen (1923). A value of $60 \%$ (calculated as glucose) was obtained; allowing for the fact that glucosamine has only $75 \%$ of the reducing power of glucose in the method used, this value would correspond to a combined galactose and mannose value of $45 \%$.

$D N A$-deoxyribose estimations indicated that the polysaccharide contains $0.5 \%(w / v)$ DNA.

Ribonucleic acid content. In view of the negligible contamination of the polysaccharide with DNA, RNA contamination of the isolated material was assessed by the ultraviolet absorption spectrum, making the necessary correction for protein contamination (assuming that all the nitrogen unaccounted for by glucosamine, etc., was present as protein). When digestion with crystalline ribonuclease was omitted during the purification procedure, the polysaccharide showed $\mathbf{7 0 - 7 5 \%}$ contamination with RNA; hydrolysis and chromatography confirmed the presence of adenine, guanine, uridine- 5 'monophosphate and cytidine-5'-monophosphate. Inclusion of the ribo- 
nuclease digestion procedure decreased contamination with RNA to the order of $7 \%$.

Total phosphorus. Micro-phosphorus determinations showed that the isolated polysaccharide contained $1.3 \%$ phosphorus. On the basis of $7 \%$ contamination with RNA and $0.5 \%$ contamination with DNA, the phosphorus unaccounted for by either DNA or RNA is of the order of $0.55 \%$.

Total nitrogen. The total nitrogen present in the isolated polysaccharide was $4.8 \%$; allowing for the nitrogen contributed by glucosamine (1.37\%), RNA $(0.7 \%)$ and DNA $(0.05 \%)$, the residual nitrogen value is $2.68 \%$.

Amino acid analysis. Two mg. of polysaccharide were hydrolysed with $1 \mathrm{ml} .6 \mathrm{~N}-\mathrm{HCl}$ in a sealed tube for $18 \mathrm{hr}$. at $110^{\circ}$, evaporated to dryness in vacuo, the residue dissolved in $100 \mu \mathrm{l}$. distilled water and chromatographed two dimensionally in butanol + acetic acid + water followed by phenol + ammonia. The following amino acids were detected: aspartic acid, glutamic acid, serine, glycine, threonine, alanine, leucine, iso-leucine, valine, methionine, proline.

\section{DISCUSSION}

Analysis of the cellular polysaccharide from Streptococcus pneumoniae, Type II, strain R 19, showed the constituent sugars to be galactose, mannose and acetylglucosamine. The presence of acetylglucosamine lends support to the proposal (Smith et al. 1957a) that the UPPacetylglucosamine present in S. pneumoniae, Types II and III, may be functional as a glycosyl donor in synthesis of the cellular polysaccharide. An extension of this investigation to the cellular polysaccharides of $S$. pneumoniae, Types I and III, has now shown that an identical sugar pattern exists for each type.

Galactose appears to be the major constituent of the sugars obtained on acid hydrolysis of the polysaccharide; this is of interest in view of the fact that the UPPglucose isolated from Streptococcus pneumoniae, Type II, strain R 19, has been found to be a mixture of UPPglucose and UPPgalactose (unpublished observation).

During the isolation of the cellular polysaccharide it was found that RNA was a major contaminant unless a ribonuclease digestion were included in the purification procedure. This may account for the observation of Wadsworth et al. (1934) that selective absorption in the ultraviolet region was characteristic of the 'pure' substance. The different phosphorus values of previous preparations $(0 \cdot 43-6.54 \%)$ may also be accounted for by the contaminating RNA. The residual 7\% RNA associated with the present preparation can probably be attributed to the residual core of RNA which is not attacked by ribonuclease.

A considerable amount of nitrogen (2.68\%) is unaccountable for in terms of glucosamine-N, RNA-N or DNA-N. From the amino acid pattern obtained it seems probable that this nitrogen is associated with protein. Attempts to remove this protein by repeated Sevag treatments and fractional alcohol precipitation of the purified polysaccharide have so far failed, nor have such procedures led to any change in the amino acid pattern. 
One of us (E.E.B.S.) is the holder of a Beit Memorial Fellowship for Medical Research. The expenses of this research were defrayed in part by a grant from the Medical Research Council, and in part by the Rankin Fund of the University of Glasgow, both of which we acknowledge with thanks.

\section{REFERENCES}

Ceriotri, G. (1955). Determination of nucleic acids in animal tissues. J. biol. Chem. 214, 59.

Consden, R. \& Stanier, W. M. (1952). Ionophoresis of sugars on paper and some applications to the analysis of protein-polysaccharide complexes. Nature, Lond. 169, 783.

Conway, E. J. (1947). Micro-Diffusion Analysis and Volumetric Error, 2nd ed. London: Crosby-Lockwood.

ENDERs, J. F. (1930). A type specific substance distinct from the specific carbohydrate in pneumococcus Type I. J. exp. Med. 52, 235.

Griswold, B. L., Humoller, F. L. \& McInTyre, A. R. (1951). Inorganic phosphates and phosphate esters in tissue extracts. Analyt. Chem. 23, 192.

Hagedorn, H. C. \& Jensen, B. N. (1923). Zur Mikrobestimmung des Blutzuckers mittels Ferricyanid. Biochem. Z. 135, 46.

Heidelberger, M. \& Kendall, F. E. (1931). Specific and non-specific polysaccharides of Type IV pneumococcus. J. exp. Med. 53, 625.

Heidelberger, M., Kendall, F. E. \& Scherp, H. W. (1936). The specific polysaccharides of Types I, II and III pneumococcus. A review of methods and data. J. exp. Med. 64, 559.

MA, T. S. \& ZuazaGA, G. (1942). Micro-Kjeldahl determination of nitrogen. A new indicator and an improved rapid method. Industr. Engng Chem. (Anal.), 14, 280.

Partridge, S. M. (1948). Filter paper partition chromatography of sugars. Biochem. J. 42, 238.

Partridge, S. M. (1949). Aniline hydrogen phthalate as a spraying reagent for chromatography of sugars. Nature, Lond. 164, 443.

PaUl, J. (1956). The chemical determination of deoxyribonucleic acid in tissue cultures. J. Biophysic. Biochem. Cytol. 2, 797.

Rondle, C. J. M. \& Morgan, W. T. J. (1955). The determination of glucosamine and galactosamine. Biochem. J. 61, 586.

SABIN, A. B. (1931). On the presence in antipneumococcus serum of type-specific protective antibody not neutralized by homologous specific soluble substance. J. exp. Med. 53, 93.

Sevag, M. G. (1934). Eine neue physikalische Enteiweisungsmethode zur Darstellung biologisch wirksamer Substanzen. Biochem. Z. 273, 419.

Smith, E. E. B., Mills, G. T. \& Harper, E. M. (1957 $a$ ). A comparison of the uridine pyrophosphoglycosyl metabolism of capsulated and non-capsulated pneumococci. J. gen. Microbiol. 16, 426.

Smith, E. E. B., Mrrls, G. T. \& Harper, E. M. (1957 b). The isolation of uridine pyrophosphogalacturonic acid from a Type I pneumococcus. Biochim. biophys. Acta, 23, 662 .

Smith, H. \& Zwartouw, H. T. (1956). The polysaccharide from Bacillus anthracis grown in vivo. Biochem. J. 63, 447.

Tillett, W. S. \& Francis, T. Jun. (1930). Serological reactions in pneumonia with a non-protein somatic fraction of pneumococcus. J. exp. Med. 52, 561.

Tillett, W. S., Goebel, W. F. \& Avery, O. T. (1930). Chemical and immunological properties of a species-specific carbohydrate of pneumococci. J. exp. Med. 52, 895. 
Wapsworth, A. \& Brown, R. (1931). Chemical and immunological studies of the pneumococcus. I. A specific antigenic carbohydrate of Type I pneumococcus. J. Immunol. 21, 245.

Wadsworth, A. \& Brown, R. (1933). Chemical and immunological studies of the pneumococcus. III. Cellular carbohydrate fractions. J. Immunol. 24, 349.

Wadsworth, A., Crowe, M. O'L. \& Smith, L. A. (1934). Absorption spectra of the carbohydrates of the pneumococcus. A preliminary note. J. Immunol. 26, 481.

WARD, H. K. (1932). An examination of the mechanism of pneumococcus immunity by means of bactericidal measurements. II. The reaction between the anticarbohydrate antibody and type-specific products of the organism. J. exp. Med. $55,519$.

Write, B. (1938). Biology of the Pneumococcus. New York: Commonwealth Fund.

WyatT, G. R. (1951). Recognition and estimation of 5-methyl cytosine in nucleic acids. Biochem. J. 48, 581.

(Received 8 April 1957) 